Cell Research (2000), 10, 311-323

\title{
Genetic aberration in primary hepatocellular carcinoma: correlation between p53 gene mutation and loss-of- hetero- zygosity on chromosome 16q21-q23 and 9p21-p23
}

\author{
Wang Gang ${ }^{1,2}$, Chang Hui Huang ${ }^{2}$, Yan ZhaO ${ }^{2}$, Ling $\mathrm{CaI}^{2}$, \\ Ying Wang ${ }^{2}$, Shi Jin Xid ${ }^{2}$, Zheng Wen Jiang ${ }^{2}$, Shuang \\ $\mathrm{YANG}^{2}$, Xin Tai ZhaO ${ }^{1}$, Wei HuanG ${ }^{2}$, Jian Ren Gu ${ }^{1, *}$ \\ ${ }^{1}$ National Laboratory for Oncogene and Related Genes, Shang- \\ hai Cancer Institute, 25/2200, Xie-tu Rd, Shanghai 200032, \\ China \\ ${ }^{2}$ Chinese Human Genome Center at Shanghai, 351 Guo Shou Jin \\ Road, Zhangjiang High Tech Park, Shanghai 201203, China
}

\begin{abstract}
To elucidate the molecular pathology underlying the development of hepatocellular carcinoma (HCC), we used 41 highly polymorphic microsatellite markers to examine 55 HCC and corresponding non-tumor liver tissues on chromosome 9, 16 and 17. Loss-of-heterozygosity ( $\mathrm{LOH}$ ) is observed with high frequency on chromosomal region 17p13 (36/55, 65 \%), 9p21p23 (28/55, 51\%), 16q21-q23 (27/55, $49 \%)$ in tumors. Meanwhile, microsatellite instability is rarely found in these microsatellite loci. Direct sequencing was performed to detect the tentative mutation of tumor suppressor genes in these regions: p53, MTS1/p16, and CDH1/E-cadherin. Within exon 5-9 of p53 gene, 14 out of 55 HCC specimens (24\%) have somatic mutations, and nucleotide deletion of this gene is reported in HCC for the first time. Mutation in MTS1/p16 is found only in one tumor case. We do not find mutations in $\mathrm{CDH} 1 / \mathrm{E}$-cadherin. Furthermore, a statistically significant correlation is present between p53 gene mutation and loss of chromosome region 16q21-q23 and 9p21-p23, which indicates that synergism between p53 inactivation and deletion of 16q21-q23 and 9p21p23 may play a role in the pathogenesis of HCC.
\end{abstract}

\footnotetext{
* Corresponding author, Tel and Fax: 0086-21-64177401; : Email: nlorg@public.sta.net.cn
} 
Genetic aberration in hepatocellular carcinoma

Key words: Hepatocellular carcinoma; 553 gene mutation; loss of heterozygosity (LOH); microsatellite marker.

\section{INTRODUCTION}

Hepatocellular carcinoma is among the most common malignancies worldwide, especially in Asia, Africa and Southern Europe. HCC usually develops from chronic inflammatory liver diseases caused by viral infection or alcohol intake that induces cirrhosis[1],[2]. Another risk factor, exposure to chemical carcinogen such as aflatoxin B1 (AFB1), is also associated with tumorigenesis of the liver[3],[4]. Like other solid tumors, it has been proposed that hepatocarcinogenesis and its progression should be a multistep process requiring the accumulation of genetic alterations. However, its precise molecular pathogenesis is far from clear.

It has been generally accepted that $\mathrm{p} 53$ gene mutation on codon 249 , position 3 can be induced by AFB1 during the interaction between DNA and chemical carcinogen, which resulted in a substitution of amino acid from Arg to Ser and the folding abnormality of DNA-binding domain of p53 protein[5],[6]. The expression pattern of enzymes for detoxification of AFB1 and DNA repair process are critical in determining the susceptibility to carcinogens at individual levels. Mutant allele or gene deletion of such enzymes such as glutathione S-transferase M1 (GSTM1) has been reported with high frequency in HCC [7]. As for HBV infection, structural or functional alteration of oncogenes or tumor suppressor genes (TSGs) resulting from HBV insertion into host genome was reported in isolated HCC cases, while HBV X protein, showing binding activity with p53 protein and trans-activation properties, has been postulated to have great significance in malignant transformation[8],[9]. Thus, synergism of both environmental factors (chemicals and virus) and genetic factors (oncogenes, TSGs and susceptibility genes) may play an important role in the development of HCCs. In recent years, direct examination of known oncogenes/TSGs has been used to explore the genes related to liver tumorigenesis[10]. Results of previous studies showed a variation of p53 mutations from various areas in terms of frequency, spectrum and timing: mutation of codon 249 is associated with AFB1 exposure in rural regions of China (Qidong) and Africa (Mozambique and Senegal) and may represent an early event during hepatocarcinogenesis, whereas different mutation spectrum of p53 was observed in Japan and big cities of China(Shanghai and Beijing)[1113]. In addition, activation or DNA amplification of c-myc and cyclin D, mutations of $\beta$ Catenin and IGFIIR/M6P have been observed in HCC[14-16]. Another approach to find the genes associated with HCCs is to screen for regions with frequent genetic alteration by using whole-genome scanning technologies including microsatellite analysis (MSA) 
and comparative genomic hybridization (CGH). Chromosome arm 1p, 4q, 6q, 8p, 13q, 16q, $17 p$ and $22 q$ have been reported as regions with frequent $\mathrm{LOH}$, while $1 \mathrm{q}, 8 \mathrm{q}, 6 \mathrm{p}$ and $17 \mathrm{q}$ are regions showing frequent DNA amplification or gains[17-20]. In this study, we analyzed the genetic loss of genomic DNA and mutation status of several genes within the deleted regions in $55 \mathrm{HCC}$ specimens, and tried to provide further information of interactions among different genetic events in the development of HCC.

\section{MATERIALS AND METHODS}

\section{Patients and specimens}

All HCC and non-tumor liver tissues were obtained from 55 patients during surgery with informed consent in hospitals of Shanghai, Qidong, and Guangxi District. Specimens were immediately put into liquid nitrogen after separation and then kept in $-70^{\circ} \mathrm{C}$. Pathological parameters of each case or tumor specimen were examined by the Department of Pathology of these hospitals (see Tab 1).

\section{DNA extraction}

Genomic DNAs of HCC and matched nontumor tissues were prepared by SDS-proteinase $\mathrm{K}$ and phenol-chloroform extraction method[21].

\section{Microsatellite polymorphism analysis}

Allelic status was assayed by PCR amplificationwith specific primer pairs flanking polymorphic microsatellite (MS) loci. All MS markers were selected from Genethon linkage map and genome public database based on chroTab.1 Clinical parameters of HCC cases

\begin{tabular}{lr}
\hline Parameter & Number \\
\hline HBsAg & 45 \\
+ & 10 \\
- & \\
Liver cirrhosis & 44 \\
+ & 5 \\
- & 6 \\
ND & \\
Tumor size & 7 \\
$<3 \mathrm{~cm}$ & 17 \\
$>3 \mathrm{~cm},<5 \mathrm{~cm}$ & 31 \\
$>5 \mathrm{~cm}$ & \\
Tumor differentiation grade ${ }^{2}$ & 8 \\
II, II-III & 33 \\
III & 13 \\
III-IV, IV & \\
Alcohol intake habit(>50g/day) & 10 \\
+ & 45 \\
- & \\
Serum AFP level & \\
$<50 \mathrm{ng} / \mathrm{ml}$ & 20 \\
$>50 \mathrm{ng} / \mathrm{ml}$ & 35 \\
Portal vein invasion of tumor cells & \\
+ & 32 \\
- & 23 \\
\hline 1. ND, not determined; & $\mathbf{2 .}$ \\
differitiation was performed according to the \\
method of Edmondson and Steiner; $\mathbf{3 .}$ \\
a- Fetoprotein. & AFP, \\
\hline
\end{tabular}
mosomal location and frequency of heterozygosity (ABI PRISM linkage mapping set version 2 panel guide, (PE Applied Biosystems). The primers were labeled with one of three different fluorescent dyes, FAM, HEX and NED (PE Applied Biosystems).

PCR amplification was carried out in 96-well plates on 9700 PCR Systems (PE Applied Biosystems). Amplified products were then diluted in the loading buffer (70\% formamide, 3.75 $\mathrm{mM}$ EDTA, $7.5 \mathrm{mg} / \mathrm{ml}$ blue dextran, $1.2 \mathrm{nM}$ Genescan 350, ROX) and loaded onto $5 \%$ polyacrylamide gel containing 7.5 M urea in the presence of size markers as described (PE Applied Biosystems). The gel image was scanned during the electrophoresis in the ABI PRISMTM 377 Sequencer (PE Applied Biosystems). Information of amplified loci such as allele size and product amount was analyzed and generated by using ABI software GeneScan version 3.0 and Genotyper version 2.0 (PE Applied Biosystems). Allelic status was determined by comparing PCR product patterns of paired tumor and nontumor liver samples. Only those genotypes demonstrating two different sized, i.e., heterozygous MS alleles can be used for evaluating allelic status, and those homozygous MS was described as “not informative". The presence of LOH was defined when the relative intensity of the two alleles in tumor genomic DNA differed from that in reference 
Genetic aberration in hepatocellular carcinoma

DNA by a factor of at least 1.50 as previously reported[22]. The loci that did not demonstrate difference beyond this threshold were termed as the absence of LOH. Microsatellite instability was defined as the presence of novel fragments in amplified products of tumor DNAs compared with those of reference DNAs.

\section{Mutation detection of $p 53$, MTS $1 / p 16$ and $C D H 1 / E$-cadherin}

The mutation detection of p53, MTS1/p16 and CDH1/E-cadherin was carried out by amplification of exons from genomic DNA with primers within flanking intron sequencesand then direct sequencing of these fragments from both sides. PCR amplification primer pairs for exon $5-9$ of p53 are as follows:

\begin{tabular}{llcc}
\hline Exon & Primer & $\operatorname{Tm}\left({ }^{\circ} \mathrm{C}\right)$ & Size(bp) \\
\hline \multirow{2}{*}{5,6} & 5'-CACTTGTGCCCTGACTTTCA-3' & 59.9 & 464 \\
& 5'-CTTAACCCCTCCTCCCAGAG-3' & 60.0 & \\
\multirow{2}{*}{$7--9$} & 5'-CTTGGGCCTGTGTTATCTCC-3' & 59.6 & \multirow{2}{*}{839} \\
& 5'-CGGCATTTTGAGTGTTAGACTG-3' & 59.8 & \\
\hline
\end{tabular}

These primers were used for both amplification and sequencing reaction. In addition, four nested sequencing primers within the amplified fragments were synthesized for ideal results of sequencing reactions ( S1: $55^{\prime}$ - A G G T T GGCTCTGACTGT-3 ’ ; S 2: 5 ' -

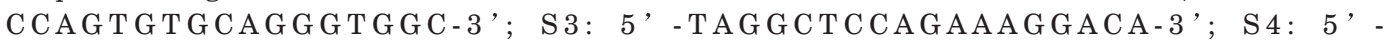
GAGCCTGGTTTTTTAAATGG-3'). The primers and PCR conditions for amplifying the three MTS1/p16 exons and all 16 exons of CDH1/E- cadherin have been described[23],[24]. By using Geneclean II/III Kit, the amplified fragments were purified as described (Bio 101 Corp.). Sequencing reactions of purified PCR products were performed in ABI Automatic Sequencer 377 as the procedure protocols for sequencing (PE Biosystems).

\section{Statistical analysis}

Statistical analysis was carried out by using the $\mathrm{X}^{2}$ test and Fisher' s Exact Test with the significant threshold $\mathrm{P}<0.025$.

\section{RESULTS}

\section{Alleotyping of $\mathrm{HCC}$}

A total of 41 microsatellite markers were used to assay the allelic status of chromosome 9, 16 and 17 in HCC. These markers covered these chromosomes quite evenly and showed high heterozygosity ( $33 \%$-93\%, with the average $64 \%$ ). Only good results of amplification reaction were used for the assessment of allelic status. Repeated experiments have been performed, verifying the reproducibility of the systems. Results showed that in HCC, LOH occurred with high frequency on chromosome region $17 \mathrm{p} 13$ (36/55, 65 \%), 9p21-p23 (28/55, $51 \%), 16 \mathrm{q} 21-\mathrm{q} 23(27 / 55,49 \%)$ and 16p13 (20/53, $38 \%)$. Out of all the genotypes obtained, only one was defined as the presence of microsatellite instability (sample D45 on locus D9S161). The genotypes defined as the presence of LOH and microsatellite instability were showed in Fig 1 . The frequency of $\mathrm{LOH}$ of each marker was summarized in Tab 2. The deletion map of specimens on these chromosomes was shown in Fig 2.

\section{Somatic mutation}

The deleted regions described above harbored the tumor suppressor gene p53 (17p13. 1), MTS1/p16 (9p21-p22) and CDH1/E-cadherin (16q22.1). We analyzed the mutation 
Wang $G$ et al.

Tab. 2 Frequency of $\mathrm{LOH}$ and Heterozygosity of each microsatellite in HCC

\begin{tabular}{|c|c|c|c|c|}
\hline Microsatellite & Location $^{1}$ & LOH\% $^{2}$ & $\mathrm{LOH} / \mathrm{Inf}^{3}$ & Heterozygosity $\%^{4}$ \\
\hline D9S288 & 9p24.1 & 32.4 & $11 / 34$ & 61.8 \\
\hline D9S286 & 9p23 & 36.8 & $14 / 38$ & 69.1 \\
\hline D9S167 & 9p22.3-p23 & 52.8 & $19 / 36$ & 65.5 \\
\hline D9S171 & 9p21.3 & 47.6 & $10 / 21$ & 38.2 \\
\hline D9S161 & 9p21.1-p21.2 & 37.5 & $12 / 32$ & 58.2 \\
\hline D9S175 & $9 \mathrm{q} 21.31$ & 18.9 & $7 / 37$ & 67.3 \\
\hline D9S167 & $9 \mathrm{q} 21.32-\mathrm{q} 21.33$ & 17.1 & $7 / 41$ & 74.5 \\
\hline D9S283 & $9 \mathrm{q} 22.1$ & 10.5 & $4 / 38$ & 69.1 \\
\hline D9S287 & $9 \mathrm{q} 22.2$ & 10.3 & $3 / 29$ & 52.7 \\
\hline D9S1690 & $9 \mathrm{q} 22.3$ & 12.8 & $5 / 39$ & 70.9 \\
\hline D9S1677 & $9 q 31.3$ & 10.3 & $3 / 29$ & 52.7 \\
\hline D9S1776 & $9 \mathrm{q} 33.1-\mathrm{q} 33.2$ & 13.8 & $4 / 29$ & 52.7 \\
\hline D9S1682 & $9 \mathrm{q} 33.3$ & 6.1 & $2 / 33$ & 60.0 \\
\hline D9S290 & $9 \mathrm{q} 34.1$ & 18.2 & $6 / 33$ & 60.0 \\
\hline D9S164 & $9 \mathrm{q} 34.1-\mathrm{q} 34.1$ & 7.9 & $3 / 38$ & 69.1 \\
\hline D9S1826 & $9 \mathrm{q} 34.1-\mathrm{q} 34.2$ & 12.5 & $5 / 40$ & 72.7 \\
\hline D16S423 & $16 \mathrm{p} 13.3$ & 32.6 & $15 / 46$ & 83.6 \\
\hline D16S3075 & $16 \mathrm{p} 13.2$ & 21.4 & $9 / 42$ & 76.4 \\
\hline D16S3103 & 16p13.1 & 22.2 & $4 / 18$ & 32.7 \\
\hline D16S3046 & $16 \mathrm{p} 12.2-\mathrm{p} 12.3$ & 20.0 & $8 / 40$ & 72.7 \\
\hline D16S3068 & 16p11.2-p12.1 & 23.1 & $9 / 39$ & 70.9 \\
\hline D16S3136 & 16p11.1-16q11.1 & 4.3 & $2 / 46$ & 83.6 \\
\hline D16S415 & $16 \mathrm{q} 12-\mathrm{q} 13$ & 21.9 & $7 / 32$ & 58.2 \\
\hline D16S408 & $16 q 13$ & 35.5 & $11 / 31$ & 56.4 \\
\hline D16S503 & $16 \mathrm{q} 21-\mathrm{q} 22.1$ & 39.3 & $11 / 28$ & 50.9 \\
\hline D16S515 & $16 \mathrm{q} 23.1$ & 47.9 & $23 / 48$ & 87.3 \\
\hline D16S516 & $16 \mathrm{q} 23.2$ & 50.0 & $11 / 22$ & 40.0 \\
\hline D16S3091 & $16 \mathrm{q} 23.3$ & 29.4 & $10 / 34$ & 61.8 \\
\hline D16S520 & $16 \mathrm{q} 24$ & 19.6 & $10 / 51$ & 92.7 \\
\hline D17S849 & $17 \mathrm{p} 13.3$ & 67.9 & $19 / 28$ & 50.9 \\
\hline D17S831 & $17 \mathrm{p} 13.3$ & 55.6 & $25 / 45$ & 81.8 \\
\hline D17S938 & $17 \mathrm{p} 13.2$ & 60.5 & $23 / 38$ & 69.1 \\
\hline D17S1852 & 17 p12 & 50.0 & $11 / 22$ & 40.0 \\
\hline D17S799 & 17p12 & 45.7 & $16 / 35$ & 63.6 \\
\hline D17S921 & 17 p12 & 61.0 & $25 / 41$ & 74.5 \\
\hline D17S1857 & 17 p12 & 6.3 & $3 / 48$ & 87.3 \\
\hline D17S1868 & $17 \mathrm{q} 21.3$ & 7.1 & $3 / 42$ & 76.5 \\
\hline D17S787 & $17 q 22$ & 18.4 & $7 / 38$ & 69.1 \\
\hline D17S949 & $17 q 23-q 24$ & 8.6 & $3 / 35$ & 63.6 \\
\hline D17S785 & $17 \mathrm{q} 25.1-\mathrm{q} 25.3$ & 22.6 & $7 / 31$ & 56.4 \\
\hline D17S784 & $17 \mathrm{q} 25.3$ & 3.7 & $1 / 27$ & 49.1 \\
\hline
\end{tabular}

1, According to the genome database at Internet site http://gdbwww.gdb.org; 2, LOH \%, the number of specimens with $\mathrm{LOH}$ divided by that of informative cases; 3, Inf, Informative cases; 4 , total number(55). (whether it is equal to Heterozygose 5\%

status of exon 5-9 of p53 gene in the $55 \mathrm{HCC}$ and corresponding non-tumor tissues. Results showed that $14(26 \%)$ specimens exhibited somatic mutation or in-frame nucleotide deletion (see Tab 3). As shown in the table, all HCCs with p53 mutation exhibited LOH on informative MS loci on 17p13, suggesting the inactivation of $\mathrm{p} 53$ gene by loss of a copy in addition with mutation of the other normal allele in these specimens. The $249^{\text {Ser }}$ mutation $(4 / 14,29 \%)$, as reported previously, was the most prevalent mutation in HCCs. Furthermore, in-frame deletion within.exon 8 and exon 9 was found in two cases. In-frame 
Genetic aberration in hepatocellular carcinoma
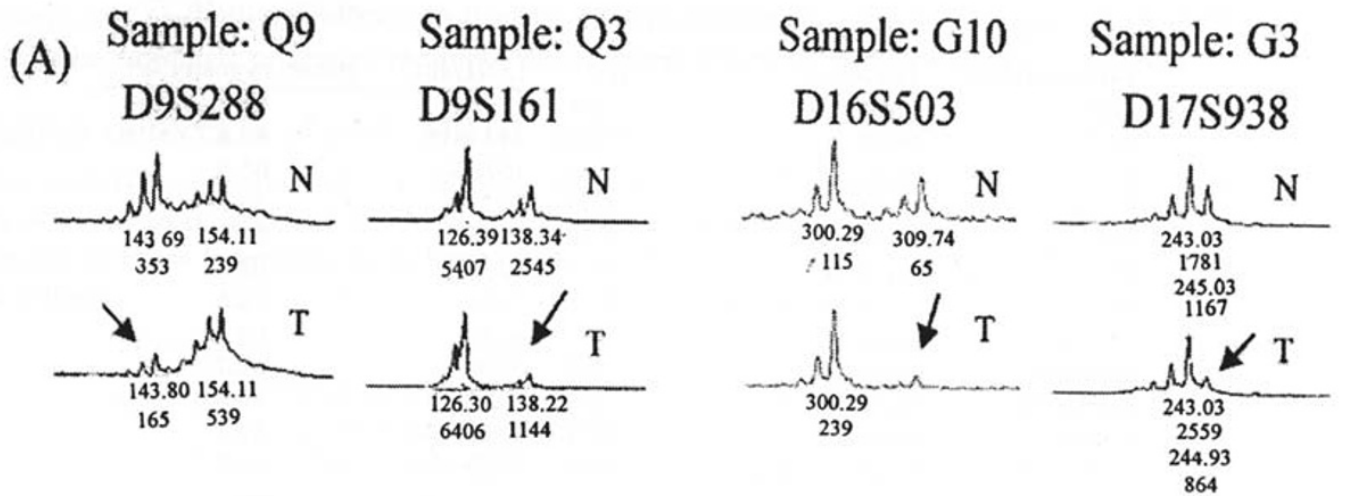

(B)

\section{Sample: D45} D9S161

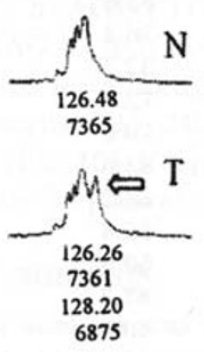

Fig 1. Genotypes of microsatellite analysis in paired HCC and reference specimens. (A) Typical allelotyping defined as the presence of LOH. Genotyping patterns of tumor tissues showed here were clear-cut different. The boxed figures under the peaks indicated the allele size and peak height. Lower shoulder peaks, differing by $2 \mathrm{bp}$ in allele size, indicated stutter bands due to the polymerase slippage during the PCR reaction. The black arrow represents the lost allele of MS compared to the reference. (B). Case of microsatellite instability. The novel allele of MS D9S161, sized 128 bp as marked by the arrow, existed in tumor specimen 51, compared with the reference.

Tab 3. HbsAg status, p53 gene mutation and LOH of HCC specimens.

\begin{tabular}{|c|c|c|c|c|c|c|c|c|}
\hline & & & Codon/exon 1 & Nucleotide $^{2}$ & Amino Acid $^{3}$ & $9 p^{4}$ & $16 q^{5}$ & $17 p^{6}$ \\
\hline G3 & + & + & $161 /$ exon5 & gcc $\rightarrow$ acc & $\mathrm{ALA} \rightarrow \mathrm{THR}$ & $+^{b}$ & + & + \\
\hline D1 & - & - & $161 /$ exon5 & $\mathrm{gcc} \rightarrow \mathrm{acc}$ & $\mathrm{ALA} \rightarrow \mathrm{THR}$ & + & - & $\mathrm{NI}^{c}$ \\
\hline D14 & + & - & $167 /$ exon5 & $\mathrm{cag} \rightarrow$ tag & GLN $\rightarrow$ Stop & + & + & + \\
\hline D20 & + & + & 213 /exon6 & $\operatorname{cga} \rightarrow$ cta & $\mathrm{ARG} \rightarrow \mathrm{LEU}$ & + & + & + \\
\hline Q4 & + & + & $226 /$ exon6 & ggc $\rightarrow$ gac & GLY $\rightarrow$ ASP & + & + & NI \\
\hline D46 & - & + & $248 /$ exon 7 & $\operatorname{cgg} \rightarrow \operatorname{ctg}$ & ARG $\rightarrow$ LEU & + & + & + \\
\hline D3 & + & + & 249/exon7 & agg $\rightarrow$ agt & ARG $\rightarrow$ SER & + & - & + \\
\hline G7 & + & - & 249/exon7 & agg $\rightarrow$ agt & ARG $\rightarrow$ SER & + & + & + \\
\hline G8 & + & + & 249/exon7 & $\mathrm{agg} \rightarrow \mathrm{agt}$ & $\mathrm{ARG} \rightarrow \mathrm{SER}$ & + & + & + \\
\hline D17 & + & + & 249/exon7 & agg $\rightarrow$ agt & ARG $\rightarrow$ SER & + & + & + \\
\hline D7 & + & + & 251/exon7 & atc $\rightarrow$ gtc & $\mathrm{ILE} \rightarrow \mathrm{VAL}$ & + & + & + \\
\hline D10 & + & + & $251 /$ exon 7 & atc $\rightarrow$ ttc & $\mathrm{ILE} \rightarrow \mathrm{PHE}$ & - & + & + \\
\hline Q12 & - & + & $\begin{array}{l}15 \text { bp del/ } \\
\text { exon } 8\end{array}$ & $\begin{array}{l}\text { del(a gag gaa } \\
\text { gag aat at)*a }\end{array}$ & $\begin{array}{l}5 \text { amino acid } \\
\text { deletion }\end{array}$ & - & + & + \\
\hline G1 & + & + & $\begin{array}{l}\text { 5bp del/ } \\
\text { exon9 }\end{array}$ & $\operatorname{del}(g \operatorname{ccc} a)^{a}$ & frame shift & - & + & + \\
\hline
\end{tabular}

1, codon/exon, the position of mutation detected and verified by direct sequencing from both directions of exons; 2, Nucleotide changes, including point mutation and small deletion; 3 , Amino acid changes, including the substitution of amino acid and small deletion with shift in reading frames, was predicted from the change of nucleotide; 4, LOH status on 9p21-p23; 5, LOH status on 16q21-q23; 6, LOH on 17p13, *5bp del (ccc aac) means small deletion of 5bp: g ccc a; a, The small deletion of p53 gene in hepatocellular carcinoma was first reported; b, This case also showed somatic mutation in MTS1/p16 located in 9p21-p22; c, NI, not informative. 
Wang $\mathrm{G}$ et al.

(a)

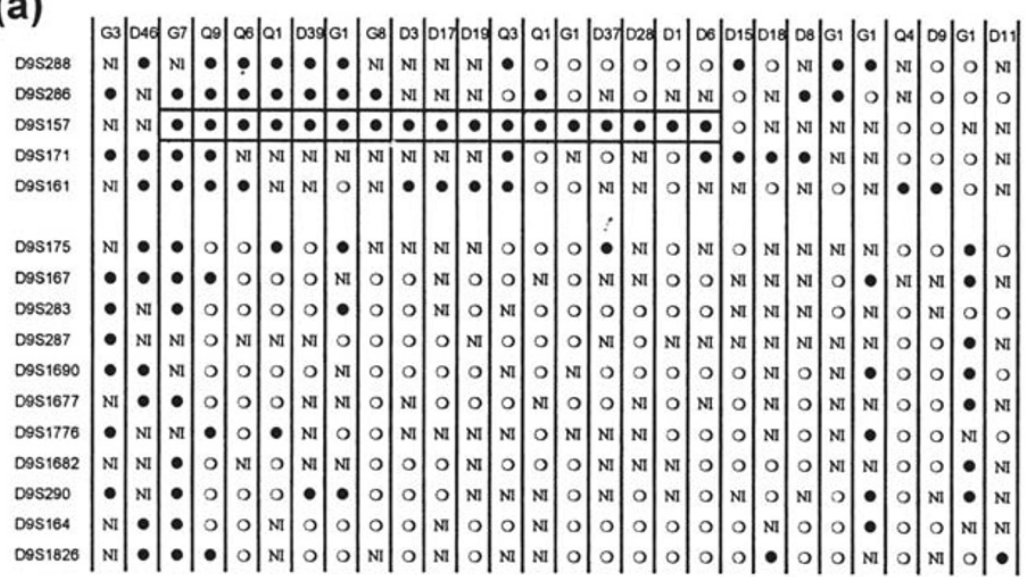

(b)

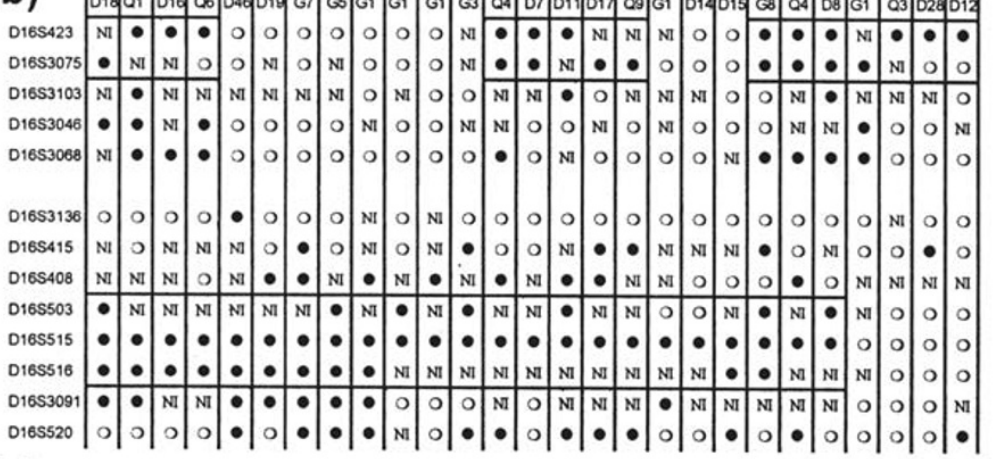

(c)

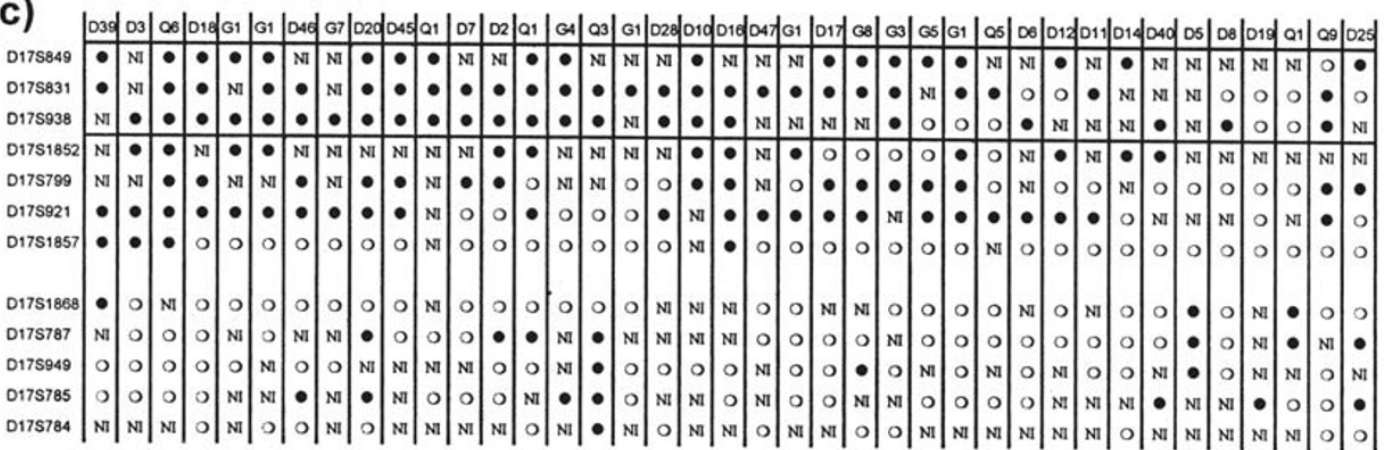

Fig 2. The deletion maps on chromosome 9, 16 and 17 in HCC. (a) Map of chromosome 9. The common deletion region in these specimens was defined between MS loci D9S286 and D9S171. (b) Map of chromosome 16. Two separate regions, one between telomere and D16S3103 (16p13) and the other between D16S503 and D16S3091 (16q21-q23), were observed. (c) Map of chromosome 17. D17S849 and D17S921, located in $17 \mathrm{p} 13$ and $17 \mathrm{p} 12$, were two loci with the highest frequency of $\mathrm{LOH}$. The boxed areas represented the common regions showing frequent $\mathrm{LOH}$ in $\mathrm{HCC}$. $\bullet$ LOH; o, retention of heterozygosity; NI, not informative. 
Genetic aberration in hepatocellular carcinoma

(A)
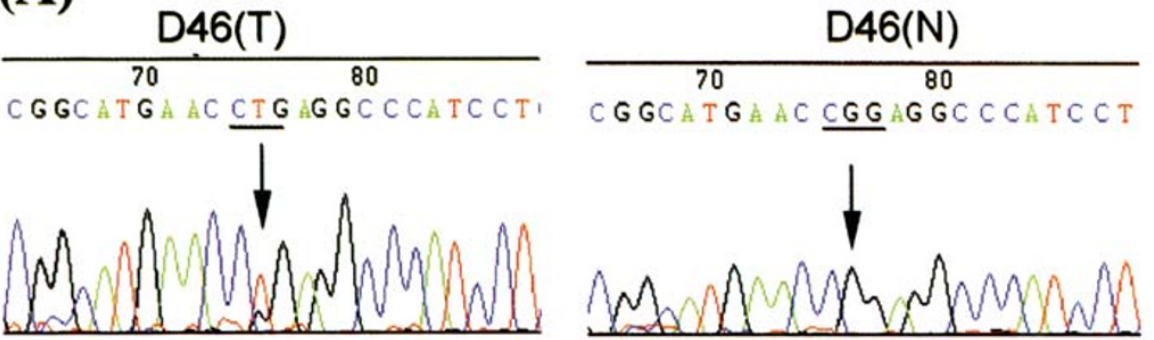

Codon248:

CGG(Arg) $\rightarrow$ CTG(Leu)

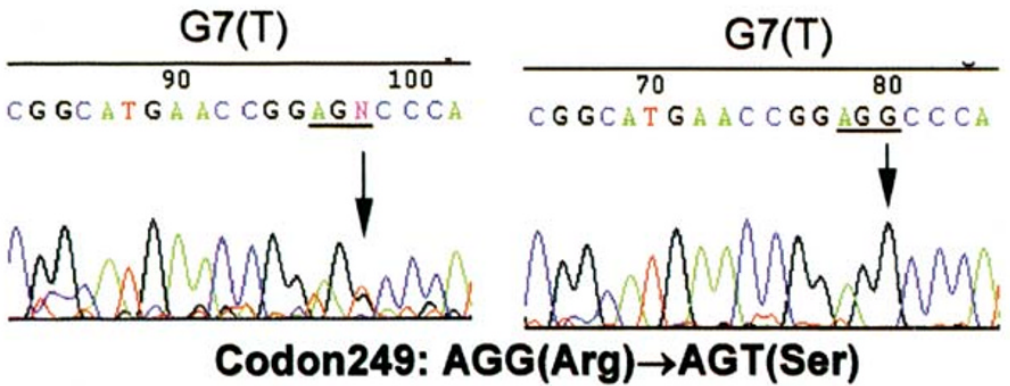

G1(T): Exon9, del 5bp(G CCC A)

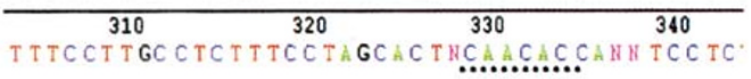

Forward sequencing

result

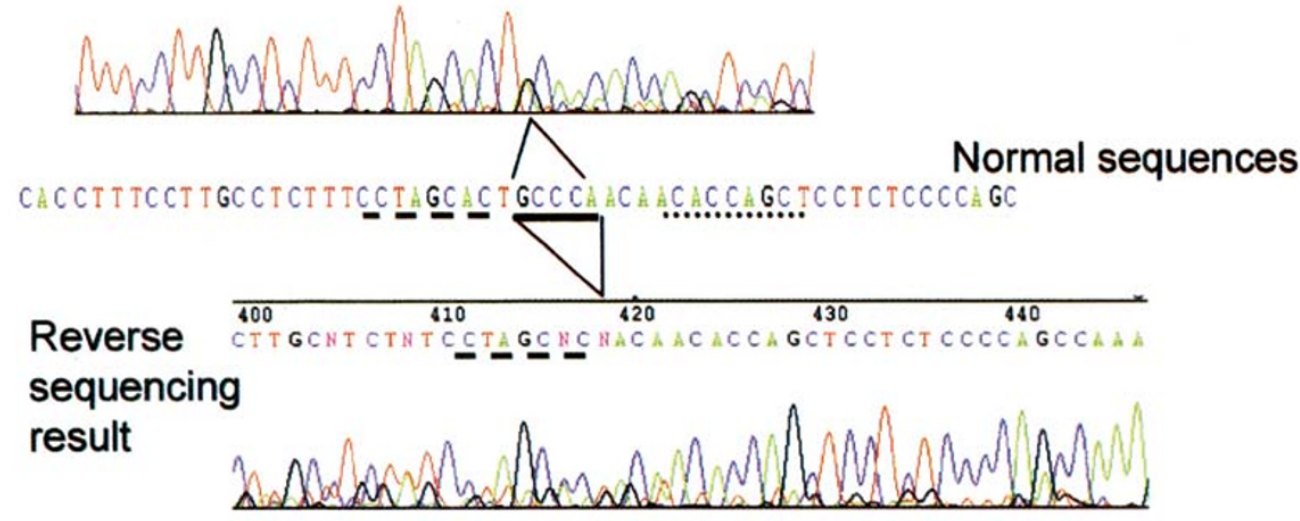


Wang $\mathrm{G}$ et al.

\section{Q12: Exon8, del 15bp (A GAG GAA GAG AAT CT)}

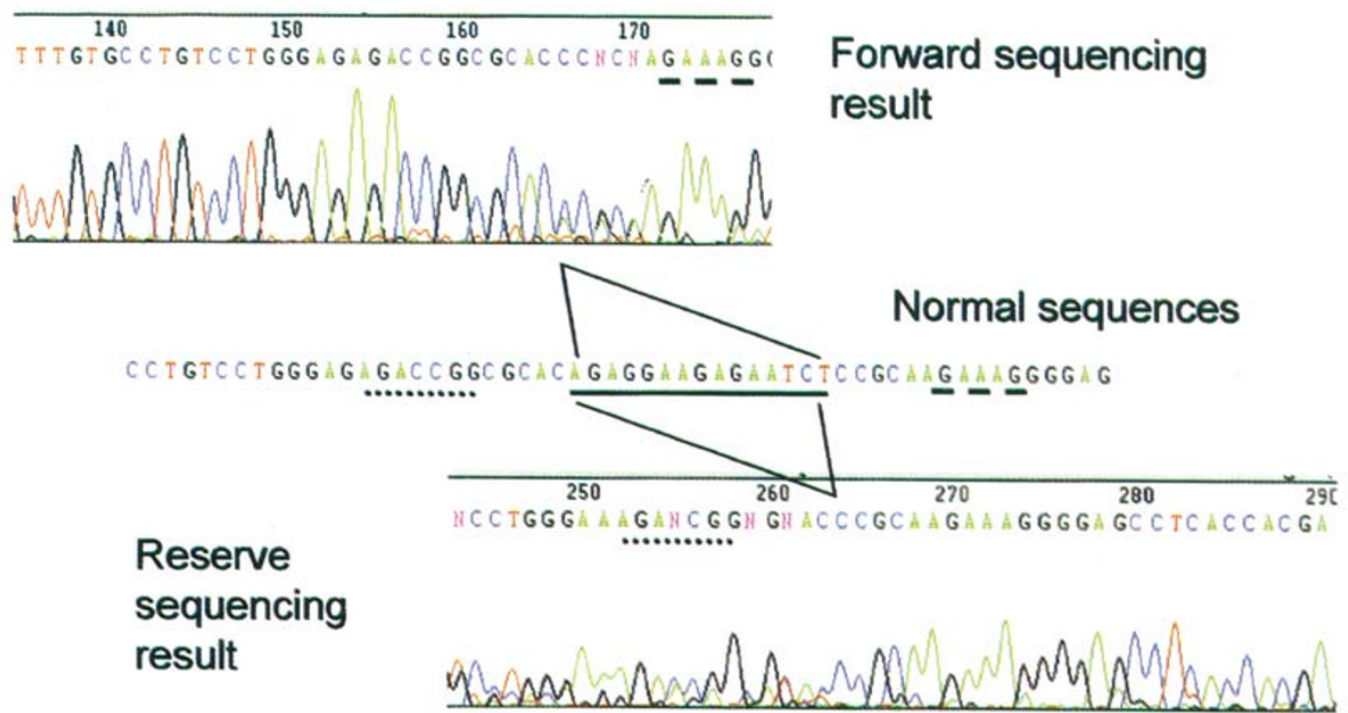

(B)

G3(T)

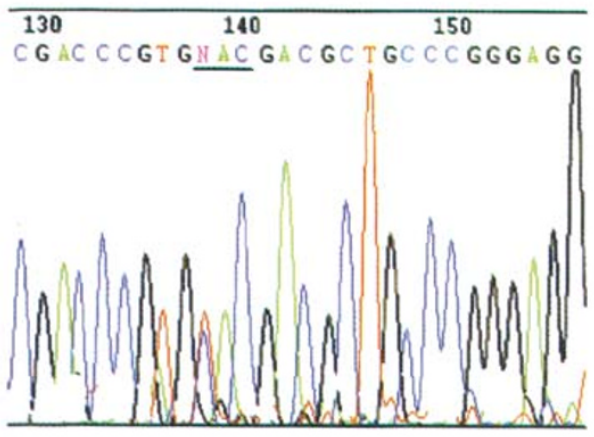

G3(N)
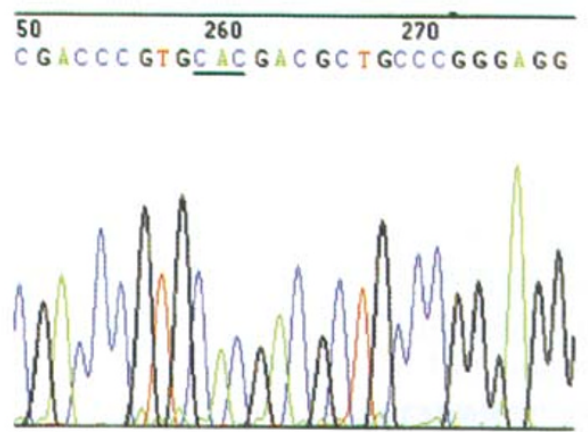

codon 83: CAC(His) $\rightarrow$ TAC(Tyr)

Fig 3. Somatic mutation of p53 and MTS/p16 in HCC. (A) p53 gene mutation. The mutation was identified by comparing both forward and reverse sequences of two kinds of matched tissues (Tumor, T; Nontumor, $\mathrm{N})$ with the standard sequence. As indicated, tumor specimen D46 and G7 showed point mutation on codon 248 and 249, respectively. A newly reported mutation type in p53, in-frame deletion, was observed in Tumor G1 (5bp deletion, exon 9) and Q12 (15bp deletion, exon 8). The complement sequence of reserve sequencing results was generated for clearer comparison by using software Chromas (By Conor McCarthy, Griffith University, Australia). (B) MTS1/p16 gene mutation in specimen G3. Nucleotide mutation of codon 83, position 1 causes the substitution of amino acid His by Tyr. 
Genetic aberration in hepatocellular carcinoma

deletion, as a new type of p53 gene mutation in HCC, was, for the first time, reported in this paper. All identified mutations in exons were verified by performing sequencing reactions from both sides. Out of 28 HCC cases with 9p deletion, one case (4\%) exhibited point mutation on codon 83, position 1 of $\mathrm{p} 16$, causing the substitution of amino acid from His to Tyr, while the matched normal liver tissues did not have this mutation. This type of point mutation has not been reported before in HCC. In addition, we analyzed all exons of CDH1/E-cadherin in $48 \mathrm{HCC}$ specimens, and none of them showed mutation, indicating that mutation of this gene was rare in HCCs. The nucleotide sequencing results showing somatic mutations were shown in Fig 3.

\section{Correlation between loss of $9 p / 16 q$ and $p 53$ point mutation}

Though we have tried to determine the significance of genetic alternations in correlation with clinical parameters of these specimens such as tumor size and differentiation, no such association could be found with the threshold $\mathrm{p}<0.05$. In addition, we investigated the association between different genetic alternation events. Among the 14 HCC cases having mutation within the exon 5-9 of p53 gene, 12 cases $(85.7 \%)$ also had LOH in $16 q 21$ q23. And out of 27 cases showing $\mathrm{LOH}$ on 16q21-q23, $12(44.4 \%)$ had somatic mutation in exon 5-9 of p53 gene. Thus, there was a statistically significant association between $\mathrm{p} 53$ gene mutation and deletion of $16 \mathrm{q} 21-\mathrm{q} 23\left(0.001<\mathrm{P}<0.005\right.$, ( $\mathrm{x}^{2}$ test $)$. Similarly, there was also a significant cor-

Tab 4. Association between p53 gene mutation and $\mathrm{LOH}$ of 9p21-p23 and 16q21-q23

\begin{tabular}{|c|c|c|}
\hline \multicolumn{3}{|c|}{ 16q LOH } \\
\hline \multicolumn{3}{|l|}{ mutation } \\
\hline+ & 12 & 2 \\
\hline - & 15 & 26 \\
\hline \multicolumn{3}{|c|}{$\left(\mathrm{x}^{2}\right.$ test, $\left.0.001<\mathrm{P}<0.005\right)$} \\
\hline \multicolumn{3}{|c|}{ 9p LOH } \\
\hline $\begin{array}{l}\text { p53 } \\
\text { mutation }\end{array}$ & + & - \\
\hline+ & 10 & 4 \\
\hline - & 18 & 23 \\
\hline$\left(\mathrm{x}^{2}\right.$ test, & $<0$. & \\
\hline
\end{tabular}
relation between $\mathrm{p} 53$ gene mutation and deletion of 9p21-p23 $\left(0.01<\mathrm{P}<0.025\right.$, ( $\mathrm{x}^{2}$ test) (see Tab 4).

\section{DISCUSSION}

In this study, we studied the allelic loss and mutation status of several genes within the deleted regions in 55 human HCCs. These HCC specimens were collected from three districts from the mainland of China: Shanghai(30), Guangxi(15) and Qidong(10). Different prevalence of AFB1 exposure was reported in these areas: intermediate in Shanghai and high in Guangxi and Qidong. Most patients are positive for HBsAg (81.8\%) and have liver cirrhosis $(89.8 \%$ ), and most HCCs from these patients can thus be considered as developed from cirrhosis with persistent HBV infection.

Allelic loss on chromosome $17 \mathrm{p}$ is among the most common genetic abnormalities in various human cancer types. p53 gene on $17 \mathrm{p} 13.1$ is thought to be the gene associated 
with the genesis of these cancers. In HCC, p53 mutations clustering at codon 249 is associated with AFB1 intake in some regions of China and Africa with high exposure of AFB1 and HBV . p53 mutations in HCC are mainly point mutations[11],[12]. In this report, we found that in-frame nucleotide deletion within exons also occurred in liver carcinoma tissues. In one case, the deletion also resulted in frame shift, inactivating the p53 protein.

MTS1/p16, encoding a negative cell cycle regulator, is located near D9S171 within chromosomal region 9p21-23. Inactivation of this gene has been found in a variety of human cancers caused by different mechanisms, including mutation, homozygous deletion of MTS1/p16 loci or hypermethylation of 5' CpG island[25-27]. In our specimens, the 9p21-p23 showed high frequency of genetic alteration, but somatic mutation of MTS1/ p16 was infrequent in primary hepatic carcinoma, a finding similar to that found among Australian population[28]. The most common mechanism of silencing the p16 gene in HCC may be due to de novo hypermethylation of 5' CpG island[26],[27].

$\mathrm{LOH}$ of chromosome 16q was observed in a variety of human cancers and reported to be associated with the progression of HCC, suggesting the loss of some genes in this region may be involved in the enhancement of tumor aggressiveness[29]. The common deletion region on 16q could be defined to 16q21-q23 (between D16S503 and D16S3091), as shown in this study. Also, we found that 16p13 (from telomere to D16S3103) was frequently lost in HCC. Mutations of CDH1/E-cadherin, located in 16q22.1, were observed in lobular breast cancer[24]. A major function of E-cadherin protein is the maintenance of cell adhesion and tissue integrity. E-cadherin deficiency in tumours would lead to changes in cell morphology and motility, so that E-cadherin is being considered to be a suppressor of cancer invasion[30]. In primary HCCs, E-cadherin expression is absent or reduced in amount as compared to normal liver tissues, which may be connected with intrahepatic metastasis of hepatocellular carcinoma[31],[32]. Another result of the reduced expression or inactivation E-cadherin gene may lie in the disruption of E-cadherin/ catenin complex and subsequently the releasing of the $\beta$-catenin into the cytoplasm in the course of hepato-carcinogenesis. $\beta$-catenin, as a part of E-cadherin/catenin complex, is involved in two major functions: cell adhesion and transmission of the proliferating signal of the Wingless/Wnt pathway. $\beta$-catenin mutation in exon 3 activate the gene itself in HCCs[15],[16],[33]. However, the mutation of this gene is rare in those HCC with allelic loss of 16q21-q23 as evidenced from data in this paper. The chanism of inactivation seemed to be $\mathrm{CpG}$ methylation around the promotor region with the deletion of the other copy [34].

The development of HCC is a multistep process, involving the accumulation of multiple genetic alterations. In the specimens we examined, p53 gene mutation is associated with allelic loss of 16q21-q23 and 9p21-p23. The phenomenon indicated the possible intimate association of $\mathrm{p} 53$ gene mutation and deletion of these regions, i.e., the requirement of inactivation of both p53 and some genes located in 16q21-q23 and 9p21-p23 in the liver tumorigenesis. The molecular basis of the observed correlation between p53 gene muta- 
Genetic aberration in hepatocellular carcinoma

tion and allelic loss in these regions remains to be elucidated, and further more research is needed to check if such correlation also exists in other HCC patients from other areas.

\section{ACKNOWLEDGEMENTS}

This work was supported by the Chinese High-Tech Program (863), Chinese Key Basic Research Project (973) and the National Natural Science Foundation of China. Gratitude was extended to Prof. Zhu CHEN for his suggestion and direction of this work.

\section{REFERENCES}

[1] Akriviadis EA, Llovet JM, Efremidis SC, et al. Hepatocellular carcinoma. Br J Surg. 1998; 85: 131931.

[2] Schafer DF, Sorrell MF. Hepatocellular carcinoma. Lancet 1999; 353:1253-7.

[3] Simonetti RG, Camma C, Fiorello F, Politi F, D' amico G, Pagliaro L. Hepatocellular carcinoma, a worldwide problem and the major risk factors. Dig Dis Sci 1991; 36:962-72.

[4] Chen CJ, Wang LY, Lu SN, et al. Elevated aflatoxin exposure and increased risk of hepatocellular carcinoma. Hepatology 1996; 24:38-42.

[5] Cho Y, Gorina S, Jeffrey PD, Pavletich NP. Crystal Structure of a p53 tumor suppressor-DNA complex: understanding tumorigenic matations. Science 1994; 265:346-55.

[6] Montesano R, Hainaut P, Wild CP. Hepatocellular carcinoma, from gene to public health. J Natl Cancer Inst. 1997; 89:1844-51.

[7] Rashid A, Wang JS, Qian GS, Lu BX, Hamilton SR, Groopman JD. Genetic alterations in hepatocellular carcinomas: association between loss of chromosome 4q and p53 gene mutations. Br J Cancer 1999; 80:59-66.

[8] Khakoo SI, Grellier LF, Soni PN, Bhattacharya S, Dusheiko GM. Etiology, screening, and treatment of hepatocellular carcinoma. Med Clin North Am. 1996; 80:1121-45.

[9] Jia L, Wang XW, Harris CC. Hepatitis B virus X protein inhibits nucleotide excision repair. Int J Cancer 1999; 80:875-9.

[10] Fujimoto Y, Hampton LL, Wirth PJ, et al. Alterations of tumor suppressor genes and allelic losses in human hepatocellular carcinomas in China. Cancer Res. 1994; 54:281-5.

[11] Oda T, Tsuda H, Scarpa A, Sakamoto M, Hirohashi S. p53 gene mutation spectrum in hepatocellular carcinoma. Cancer Res. 1992; 52:6358-64.

[12] Li DZ, Cao YP, He LP, Wang NJ, Gu JR. Aberrations of p53 in human hepatocellular carcinoma. Carcinogenesis 1993; 14:169-73.

[13] Shi CY, Phang TW, Lin Y, et al. Codon 249 mutation of the p53 gene is a rare event in hepatocellular carcinomas from ethinic Chinese in Singapore. Br J Cancer 1995; 72:146-9.

[14] Yamada T, De Souza AT, Finkelstein S, Jirtle RL. Loss of the gene encoding mannose 6-phosphate/ insulin-like growth factor II receptor is an early event in liver carcinogenesis. Proc Natl Acad Sci USA 1997; 94:10351-5.

[15] De La Coste A, Romagnolo B, Billuart P, et al. Somatic mutations of the beta-catenin gene are frequent in mouse and human hepatocellular carcinomas. Proc Natl Acad Sci USA 1998; 95:8847-51.

[16] Huang H, Fujii H, Sankila A, et al. b-catenin mutations are frequent in human hepatocellular carcinomas associated with hepatitis C virus infection. Am J Pathol 1999; 155:1795-801.

[17] Marchio A, Meddeb M, Pineau P, et al. Recurrent chromosomal abnormalities in hepatocellular carcinoma detected by comparative genomic hybridization. Genes Chromosomes Cancer 1997; 18: $59-65$.

[18] Nagai H, Pineau P, Tiollais P, Buendia MA, Dejean A. Comprehensive allelotyping of human 
hepatocellular carcinoma. Oncogene 1997; 14:2927-33.

[19] Piao Z, Park C, Park JH, Kim H. Allelotyping analysis of hepatocellular carcinoma, Int J Cancer 1998; 75:29-33.

[20] Wong N, Lai P, Lee SW, et al. Assessment of genetic changes in hepatocellular carcinoma by comparative genomic hybridization analysis: relationship to disease stage, tumor size, and cirrhosis. Am J Pathol 1999; 154:37-43.

[21] Maniatis T, Fritsch J, Sambrook J. Molecular Cloning (a laboratory manual). Cold Spring Harbor Laboratory $1989 ; 9.37-9.57$.

[22] Cunningham JM, Shan A, Wick MJ, et al. Allelic imbalance and microsatellite instability in prostatic adenocarcinoma. Cancer Res. 1996; 56:4475-82.

[23] Hussussian CJ, Struewing JP, Goldstein AM, et al. Germline p16 mutations in familial melanoma. Nat Genet 1994; 8:15-21.

[24] Berx G, Cleton-Jansen AM, Nollet F, et al. E-cadherin is a tumour/invasion suppressor gene mutated in human lobular breast cancers. EMBO J 1995; 14:6107-15.

[25] Kim JR, Kim SY, Kim MJ, Kim JH. Alterations of CDKN2 (MTS1/p16INK4A) gene in paraffin-embedded tumor tissues of human stomach, lung, cervix and liver cancers. Exp Mol Med 1998; 30:109-14.

[26] Liew CT, Li HM, Lo KW, et al. High frequency of p16INK4A gene alterations in hepatocellular carcinoma. Oncogene 1999; 18:789-95.

[27] Nuovo GJ, Plaia TW, Belinsky SA, Baylin SB, Herman JG. In situ detection of the hypermethylationinduced inactivation of the p16 gene as an early event in oncogenesis. Proc Natl Acad Sci USA 1999; 96:12754-9.

[28] Biden K, Young J, Buttenshaw R, et al. Frequency of mutation and deletion of the tumor suppressor gene CDKN2A (MTS1/p16) in hepatocellular carcinoma from an Australian population. Hepatology 1997; 25:593-7.

[29] Tsuda H, Zhang WD, Shimosato Y, et al. Allele loss on chromosome 16 associated with progression of human hepatocellular carcinoma. Proc Natl Acad Sci USA 1990; 87:6791-4.

[30] Handschuh G, Candidus S, Luber B, et al. Tumour-associated E-cadherin mutations alter cellular morphology, decrease cellular adhesion and increase cellular motility. Oncogene 1999; 18:4301-12.

[31] Kozyraki R, Scoazec JY, Flejou JF, et al. Expression of cadherins and a-catenin in primary epithelial tumors of the liver. Gastroenterology 1996; 110:1137-49.

[32] Osada T, Sakamoto M, Ino Y, et al. E-cadherin is involved in the intrahepatic metastasis of hepatocellular carcinoma. Hepatology 1996; 24:1460-7.

[33] Miyoshi Y, Iwao K, Nagasawa Y, et al. Activation of the b-catenin gene in primary hepatocellular carcinomas by somatic alterations involving exon 3. Cancer Res 1998; 58:2524-7.

[34] Kanai Y, Ushijima S, Hui AM, et al. The E-cadherin gene is silenced by CpG methylation in human hepatocellular carcinomas. Int J Cancer 1997; 71:355-9.

Received May-19-2000. : Revised Nov-7-2000. : Accepted Nov-10-2000. 